Article

\title{
Occurrence and Exposure Assessment of Mycotoxins in Ready-to-Eat Tree Nut Products through Ultra-High Performance Liquid Chromatography Coupled with High Resolution Q-Orbitrap Mass Spectrometry
}

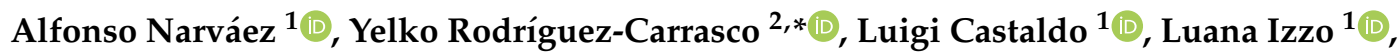 \\ Giulia Graziani $^{1}{ }^{(D)}$ and Alberto Ritieni ${ }^{1}$ (D) \\ 1 Department of Pharmacy, Faculty of Pharmacy, University of Naples "Federico II", Via Domenico \\ Montesano 49, 80131 Naples, Italy; alfonso.narvaezsimon@unina.it (A.N.); luigi.castaldo2@unina.it (L.C.); \\ luana.izzo@unina.it (L.I.); giulia.graziani@unina.it (G.G.); alberto.ritieni@unina.it (A.R.) \\ 2 Laboratory of Food Chemistry and Toxicology, Faculty of Pharmacy, University of Valencia, \\ Av. Vicent Andrés Estellés s/n, Burjassot, 46100 València, Spain \\ * Correspondence: yelko.rodriguez@uv.es; Tel.: +34-96-3544-117; Fax: +34-96-3544-954
}

Received: 31 July 2020; Accepted: 24 August 2020; Published: 25 August 2020

\begin{abstract}
Tree nuts have become popular snacks due to their attributed benefits in the health state. Nevertheless, their susceptibility to fungal contamination lead to the occurrence of potentially dangerous mycotoxins. Hence, the aim of this work was to evaluate the presence of mycotoxins in ready-to-eat almonds, walnuts, and pistachios from Italian markets. The most relevant mycotoxin found in almonds was $\alpha$-zearalanol in $18 \%$ of samples $(n=17)$ ranging from 3.70 to $4.54 \mu \mathrm{g} / \mathrm{kg}$. Walnut samples showed frequent contamination with alternariol, present in $53 \%$ of samples $(n=22)$ at levels from 0.29 to $1.65 \mu \mathrm{g} / \mathrm{kg}$. Pistachios $(n=15)$ were the most contaminated commodity, with $\beta$-zearalenol as the most prevalent toxin present in $59 \%$ of samples ranging from 0.96 to $8.60 \mu \mathrm{g} / \mathrm{kg}$. In the worst-case scenario, the exposure to zearalenone-derived forms accounted for $15.6 \%$ of the tolerable daily intake, whereas it meant $12.4 \%$ and $21.2 \%$ of the threshold of toxicological concern for alternariol and alternariol monomethyl-ether, respectively. The results highlighted the extensive presence of Alternaria toxins and zearalenone-derived forms, scarcely studied in ready-to-eat tree nut products, highlighting the necessity to include these mycotoxins in analytical methods to perform more realistic risk assessments.
\end{abstract}

Keywords: almonds; pistachios; walnuts; mycotoxins; Q-Exactive Orbitrap; risk characterization

\section{Introduction}

Tree nuts have become a popular alternative to unhealthy snacks due to their attributed benefits. The intake of tree nuts has been related to a lower risk of suffering from cardiovascular diseases through several mechanisms, and they can also act as antioxidant suppliers [1-4]. According to the International Nut and Dried Fruit Council (INC), the annual production of tree nut products has increased over the last ten years, especially forn almonds, walnuts and pistachios, reaching a maximum of 4.6 million metric tons in 2019 and highlighting a global trend in tree nut consumption [5].

Nevertheless, tree nuts are susceptible to fungal growth that can occur for several reasons related to environmental factors, such as moisture and temperature. In addition, improper post-harvest practices and storage conditions can also promote fungal contamination [6]. As a consequence of these mentioned factors, mycotoxins could also be expected in crops. These are secondary metabolites produced by several filamentous fungi, mainly Alternaria, Aspergillus, Claviceps, Fusarium, and Penicillium spp., 
which can exert severe adverse effects including neurotoxicity, nephrotoxicity, immunosuppression, or carcinogenesis [7]. According to the carcinogenic potential, some mycotoxins have been included in the list of human carcinogens released by the International Agency for Research on Cancer (IARC).

In order to control the content of potentially dangerous mycotoxins in ready-to-eat tree nut products, the European Commission released the Regulation (EC) 1881/2006 [8] amended by Regulation (EU) 165/2010 [9] setting maximum limits (MLs) for certain mycotoxins. Almonds and pistachios cannot exceed $8 \mu \mathrm{g} / \mathrm{kg}$ for aflatoxin B1 and $10 \mu \mathrm{g} / \mathrm{kg}$ for the sum of aflatoxin B1, B2, G1, and G2, whereas MLs in walnuts were set at 2 and $4 \mu \mathrm{g} / \mathrm{kg}$, respectively. However, different mycotoxins could be expected due to the susceptibility of tree nuts to fungal contamination. In this line, Aspergillus and Fusarium genera have been characterized as other major pathogens in tree nuts, so their secondary toxic metabolites could also be expected $[6,10,11]$. Alongside aflatoxins, relevant toxins from the Fusarium genus included in the IARC classification, such as T-2 or zearalenone, have been evaluated in tree nut products [12-17]. However, zearalenone-derived forms have been scarcely studied and, recently, the European Food Safety Authority (EFSA) highlighted the necessity to include these metabolites in risk assessment studies due to their estrogenic activity [18]. Furthermore, the presence of other mycotoxins-producing fungi such as Alternaria, able to produce the genotoxic compounds alternariol monomethyl-ether (AME) and alternariol (AOH), has been detected in tree nuts [11]. According to the EFSA CONTAM Panel, these mycotoxins have been scarcely studied, so the toxicological potential is still unknown, and seems to be major contributors to mycotoxin exposure in several commodities [19]. Therefore, there is a necessity to develop analytical methods able to detect and quantify these less studied mycotoxins, since they could also contribute towards overall exposure when consuming ready-to-eat nut products.

To overcome this, sensitive methods are required in order to detect low levels of mycotoxins occurring in tree nut products. In addition, environmental conditions, geographical area, or harvest practices can lead to a strong variety among products regarding mycotoxin occurrence, so constant monitoring based on sensitive and multi-analyte methods are required for having proper mycotoxin profiles. The most recent methods for detecting mycotoxins in tree nuts are based on liquid chromatography coupled with tandem mass spectrometry [12-17]. However, other alternatives are able to provide a more precise detection and quantification. The use of high-resolution mass spectrometry stands as the best alternative when performing simultaneous determinations of analytes. Identification based on full scan-all ion fragmentation analysis represents an improvement in mass accuracy when compared to traditional multiple reaction monitoring analysis based on triple quadrupole [20]. Furthermore, Q-Orbitrap offers a better performance than other high-resolution mass spectrometers for low $\mathrm{m} / \mathrm{z}$ compounds, as most mycotoxins. Therefore, the aim of this work was to evaluate the presence of eighteen mycotoxins from different genera in ready-to-eat tree nut products $(n=54)$, including almonds, walnuts, and pistachios from Italian markets through ultra-high performance liquid chromatography coupled with high-resolution Q-Orbitrap mass spectrometry. To achieve this, a single QuEChERS-based extraction was validated in the three commodities. In addition, the risk characterization resulting from mycotoxin contamination in ready-to-eat tree nut products was performed in the Italian population for the first time.

\section{Results}

\subsection{Analytical Method Validation}

The proposed methodology was validated for the simultaneous detection and quantification of 18 mycotoxins in almonds, walnuts, and pistachios. Results are shown in Table 1 Linearity, expressed through correlation coefficient $\left(\mathrm{R}^{2}\right)$, ranged from 0.9908 to 0.9998 for all compounds analyzed. The matrix effect was quantified through the percentage of signal suppression/enhancement (\%SSE) ranging from 77 to $120 \%$, from 74 to $148 \%$, and from 82 to $149 \%$ in almond, walnut, and pistachio, respectively. There were only two analytes out of the range $80-120 \%$ : AME showed a $\%$ SEE of $148 \%$ and $149 \%$ in pistachio and almond, respectively, whereas \%SEE for ENNB were $77 \%$ and $74 \%$ in almond and pistachio. In order to avoid miscalculation, matrix-matched calibration curves were used for quantification purposes. Despite 
the complexity of those matrices consisting mainly of proteins and fatty acids, a simple acetonitrile-based extraction including a clean-up step with C18 was enough to almost completely remove the matrix interference. The method also displayed a high sensitivity, with limits of quantification (LOQs) ranging from 0.20 to $0.78 \mu \mathrm{g} / \mathrm{kg}$ for all the analytes in each matrix. The recovery studies showed satisfactory results. For almonds, values ranged from 81 to $106 \%$ at the highest fortification level $(20 \mu \mathrm{g} / \mathrm{kg})$, from 73 to $95 \%$ at a medium level $(5 \mu \mathrm{g} / \mathrm{kg})$, and from 71 to $95 \%$ at the lowest level $(1 \mu \mathrm{g} / \mathrm{kg})$. Similarly, walnuts showed values from 79 to $105 \%$, 70 to $99 \%$, and 71 to $100 \%$ for the highest, medium, and lowest levels, respectively. Finally, recovery values for mycotoxins in pistachios ranged from 80 to $113 \%$, from 70 to $105 \%$, and 72 to $107 \%$ for the highest, medium, and lowest fortification levels. The precision evaluated through RSD $_{\mathrm{r}}$ and $\mathrm{RSD}_{\mathrm{R}}$ was below $20 \%$ for all the analytes at three spiking levels.

Table 1. Method performance in almonds, walnuts, pistachios.

\begin{tabular}{|c|c|c|c|c|c|}
\hline \multirow[b]{2}{*}{ Analyte } & \multirow[b]{2}{*}{ SSE (\%) } & \multicolumn{3}{|c|}{ Recovery $(\%)\left(\operatorname{RSD}_{\mathrm{R}}(\%)\right)$} & \multirow[b]{2}{*}{ LOQ (ng/g) } \\
\hline & & $20 \mathrm{ng} / \mathrm{g}$ & $5 \mathrm{ng} / \mathrm{g}$ & $1 \mathrm{ng} / \mathrm{g}$ & \\
\hline \multicolumn{6}{|c|}{ almonds } \\
\hline $\mathrm{NEO}$ & 106 & $83(12)$ & $77(16)$ & $88(7)$ & 0.78 \\
\hline AFG2 & 101 & $88(16)$ & $82(19)$ & $78(14)$ & 0.20 \\
\hline AFG1 & 111 & $83(20)$ & $78(20)$ & $82(13)$ & 0.39 \\
\hline AFB2 & 106 & $93(15)$ & $94(16)$ & $83(12)$ & 0.20 \\
\hline AFB1 & 117 & $100(10)$ & 95 (15) & $95(5)$ & 0.39 \\
\hline HT-2 & 115 & $105(8)$ & 89 (17) & $79(8)$ & 0.78 \\
\hline A-ZAL & 102 & $88(11)$ & $92(12)$ & $83(10)$ & 0.39 \\
\hline A-ZOL & 109 & $92(7)$ & $88(9)$ & $87(6)$ & 0.78 \\
\hline $\mathrm{AOH}$ & 105 & $81(14)$ & $73(14)$ & $71(14)$ & 0.20 \\
\hline $\mathrm{T}-2$ & 114 & $104(16)$ & $87(11)$ & $89(13)$ & 0.78 \\
\hline B-ZAL & 118 & $96(10)$ & 95 (13) & $89(10)$ & 0.78 \\
\hline B-ZOL & 98 & $95(9)$ & $90(15)$ & $76(9)$ & 0.20 \\
\hline ZON & 120 & $94(18)$ & $81(17)$ & $86(18)$ & 0.20 \\
\hline AME & 149 & $94(15)$ & $85(16)$ & $81(15)$ & 0.78 \\
\hline ENN B & 77 & $94(6)$ & $90(9)$ & $98(10)$ & 0.78 \\
\hline ENN B1 & 106 & $106(14)$ & $84(13)$ & $74(10)$ & 0.78 \\
\hline ENN A1 & 111 & $87(3)$ & $86(5)$ & $95(18)$ & 0.39 \\
\hline ENN A & 102 & $86(12)$ & $83(13)$ & $89(12)$ & 0.78 \\
\hline \multicolumn{6}{|c|}{ walnuts } \\
\hline NEO & 91 & $85(9)$ & $81(14)$ & $92(10)$ & 0.78 \\
\hline AFG2 & 93 & $85(5)$ & $78(9)$ & $82(10)$ & 0.20 \\
\hline AFG1 & 91 & $79(5)$ & $70(8)$ & $76(11)$ & 0.78 \\
\hline AFB2 & 103 & $91(4)$ & $84(8)$ & $79(12)$ & 0.39 \\
\hline AFB1 & 97 & $102(6)$ & $83(12)$ & $78(10)$ & 0.39 \\
\hline HT-2 & 107 & $97(9)$ & $88(11)$ & $76(9)$ & 0.78 \\
\hline A-ZAL & 103 & $99(10)$ & $81(12)$ & $100(9)$ & 0.78 \\
\hline A-ZOL & 110 & $88(7)$ & $78(15)$ & $75(9)$ & 0.78 \\
\hline $\mathrm{AOH}$ & 105 & $83(4)$ & $71(6)$ & $74(8)$ & 0.20 \\
\hline $\mathrm{T}-2$ & 96 & $86(10)$ & $84(13)$ & $79(8)$ & 0.78 \\
\hline B-ZAL & 105 & $95(5)$ & $91(11)$ & $99(12)$ & 0.78 \\
\hline B-ZOL & 97 & $94(7)$ & $85(7)$ & $95(12)$ & 0.20 \\
\hline ZON & 100 & $81(7)$ & $78(7)$ & $73(5)$ & 0.20 \\
\hline AME & 114 & $80(7)$ & $74(9)$ & $81(15)$ & 0.78 \\
\hline ENN B & 74 & $101(5)$ & $90(9)$ & $84(16)$ & 0.78 \\
\hline ENN B1 & 99 & $88(8)$ & $89(10)$ & $76(8)$ & 0.78 \\
\hline ENN A1 & 96 & $105(8)$ & $99(9)$ & $76(13)$ & 0.78 \\
\hline ENN A & 107 & $99(8)$ & $87(15)$ & $86(8)$ & 0.78 \\
\hline \multicolumn{6}{|c|}{ pistachios } \\
\hline NEO & 103 & $86(10)$ & $75(14)$ & $72(8)$ & 0.78 \\
\hline AFG2 & 82 & $106(10)$ & $82(14)$ & $82(9)$ & 0.39 \\
\hline AFG1 & 91 & $80(11)$ & $70(11)$ & $73(6)$ & 0.78 \\
\hline AFB2 & 87 & $113(10)$ & $103(11)$ & $97(7)$ & 0.39 \\
\hline AFB1 & 94 & $87(18)$ & $82(18)$ & 79 (13) & 0.39 \\
\hline HT-2 & 105 & $91(14)$ & 85 (17) & $88(14)$ & 0.78 \\
\hline A-ZAL & 86 & 99 (13) & 99 (16) & 88 (17) & 0.78 \\
\hline A-ZOL & 97 & 83 (15) & 85 (15) & $89(7)$ & 0.78 \\
\hline $\mathrm{AOH}$ & 83 & 84 (16) & 77 (17) & 83 (13) & 0.39 \\
\hline $\mathrm{T}-2$ & 85 & $92(11)$ & $98(14)$ & 85 (18) & 0.78 \\
\hline B-ZAL & 96 & $87(10)$ & $89(15)$ & $81(9)$ & 0.78 \\
\hline B-ZOL & 112 & $92(9)$ & $92(13)$ & 89 (12) & 0.78 \\
\hline $\mathrm{ZON}$ & 118 & $104(9)$ & $105(9)$ & 107 (13) & 0.20 \\
\hline AME & 148 & 87 (10) & 77 (16) & 75 (14) & 0.78 \\
\hline ENN B & 115 & 99 (14) & $92(16)$ & $83(15)$ & 0.78 \\
\hline ENN B1 & 116 & $102(6)$ & $94(8)$ & $96(16)$ & 0.78 \\
\hline ENN A1 & 118 & 105 (13) & $99(16)$ & $96(13)$ & 0.78 \\
\hline ENN A & 114 & $100(14)$ & $92(17)$ & $96(15)$ & 0.78 \\
\hline
\end{tabular}


Several multi-mycotoxin methods for tree nut products based on QuEChERS methodology have been recently published, as shown in Table 2. Although methodologies are focused on detecting aflatoxins since they are the only regulated mycotoxins in tree nuts, less attention has been put into Fusarium and Alternaria mycotoxins, which are a common genera causing fungal contamination in almonds, pistachios, and walnuts, as stated by Marín and Ramos [10] and Escrivá, Oueslati, Font, and Manyes [11]. In addition, ZEN-derived forms have also been here validated for their simultaneous detection, as recommended by the EFSA [18]. The main feature of the present methodology lies in its high sensitivity when compared to previous ones, with LOQs $\leq 0.78 \mu \mathrm{g} / \mathrm{kg}$. Sensitivity also plays a key role when performing exposure assessment studies, allowing a more realistic analysis and avoiding underestimation of mycotoxins as highlighted by the EFSA.

Table 2. Quantitative methods for multi-mycotoxin detection in several tree nut products.

\begin{tabular}{|c|c|c|c|c|}
\hline Analytes $(n)$ & Method & Sample Treatment & Sensitivity $(\mu \mathrm{g} / \mathrm{kg})$ & References \\
\hline $\begin{array}{l}\text { Aflatoxins (B1, B2, G1, G2), CIT, DON, } \\
\text { FB1, FB2, FUS-X, HT-2, OTA, T-2, STE, } \\
\text { ZEN (14) }\end{array}$ & UHPLC-MS/MS & QuEChERS-DLLME & $0.61-150$ & $\begin{array}{l}\text { Arroyo-Manzanares et al., } \\
2013 \text { [12] }\end{array}$ \\
\hline $\begin{array}{l}\text { Aflatoxins (B1, B2, G1, G2), BEA, DAS, } \\
\text { enniatins (A, A1, B, B1), FB1, FB2, FB3, } \\
\text { HT-2, OTA, T-2 (16) }\end{array}$ & LC-MS/MS & $\begin{array}{l}\text { QuEChERS-SPE } \\
\text { cartridge }\end{array}$ & $0.2-45$ & Azaiez et al., 2014 [13] \\
\hline $\begin{array}{c}\text { Aflatoxins (B1, B2, G1, G2), DAS, } \\
\text { 3AC-DON, 15AC-DON, DON, FB1, } \\
\text { FB2, FUS-X, HT-2, NEO, OTA, T-2, } \\
\text { ZEN (16) }\end{array}$ & LC-MS/MS & $\begin{array}{l}\text { QuEChERS-Z-Sep }^{+} \\
+ \text {C18 }\end{array}$ & $1.25-5$ & Cunha et al., 2018 [14] \\
\hline $\begin{array}{l}\text { Aflatoxins (B1, B2, G1, G2), AME, } \\
\text { AOH, BEA, enniatins (A, A1, B, B1), } \\
\text { OTA, OTB, T-2, TEN, ZEN (16) }\end{array}$ & UPLC-MS/MS & QuEChERS-C18 & $0.1-5$ & Wang et al., 2018 [15] \\
\hline $\begin{array}{l}\text { 3-ADON, aflatoxins (B1, B2, G1, G2, } \\
\text { M1), DAS, ERGC1, ERGC2, FB1, FB2, } \\
\text { GLI, HT-2, OTA, T-2, } \alpha-Z E L, \text { ZEN (17) }\end{array}$ & $\begin{array}{l}\text { Nano flow } \\
\text { LC-HRMS }\end{array}$ & $\begin{array}{l}\text { QuEChERS } \\
\text { EMR-Lipid }\end{array}$ & $0.05-5$ & Alcantara et al., 2019 [16] \\
\hline $\begin{array}{c}\text { Aflatoxins (B1, B2, G1, G2), } \alpha \text {-ZEL, } \\
\text { ZEN (6) }\end{array}$ & UHPLC-MS/MS & QuEChERS-C18 & $0.5-1$ & Hidalgo et al., 2019 [17] \\
\hline $\begin{array}{c}\text { Aflatoxins (B1, B2, G1, G2), AME, } \\
\text { AOH, enniatins (A, A1, B, B2), HT-2, } \\
\text { NEO, T-2, } \alpha \text {-ZAL, } \alpha \text {-ZEL, } \beta \text {-ZAL, } \\
\beta \text {-ZEL, ZEN (18) }\end{array}$ & UHPLC-HRMS & QuEChERS-C18 & $0.2-0.78$ & Present work \\
\hline \multicolumn{5}{|c|}{ 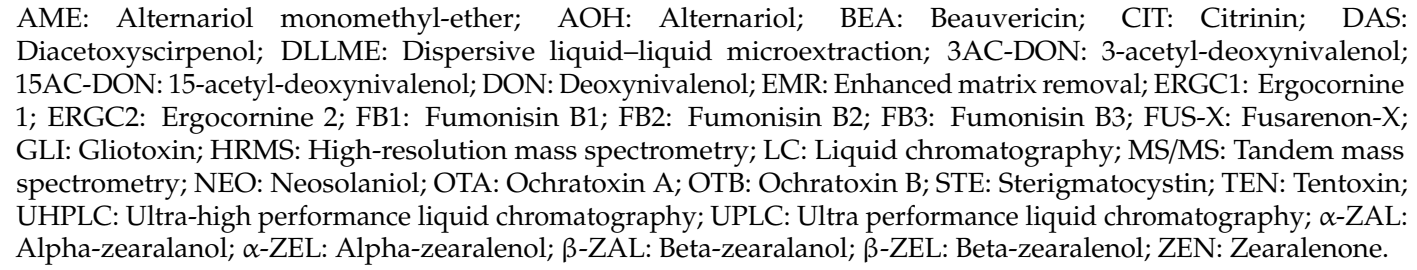 } \\
\hline
\end{tabular}

\subsection{Analysis of Real Samples}

Up to nine different mycotoxins were detected and quantified in the here-analyzed samples. Results are shown in Table 3. At least one mycotoxin occurred in 33 out of 54 nut products. The most commonly found mycotoxins belong to Fusarium species, whereas Alternaria metabolites were also found in all the studied commodities.

Referring to almonds $(n=17)$, five mycotoxins were identified in $41 \%$ of samples. The most relevant compound was $\alpha$-ZAL, a Fusarium toxin that results from the metabolism of its parental mycotoxin, ZEN. This toxin was present in $18 \%$ of the samples, ranging from 3.70 to $4.54 \mu \mathrm{g} / \mathrm{kg}$. $\beta-Z E L$, another product from the metabolization of ZEN, was found in $12 \%$ of samples at low levels going from 0.46 up to $0.62 \mu \mathrm{g} / \mathrm{kg}$. ZEN has also been studied in almonds, and contamination at 1.2 and 3.48 $\mu \mathrm{g} / \mathrm{kg}$ was reported by Škrbić, et al. [21] in the two analyzed samples. According to the present results, ZEN metabolites resulted as the major contaminants in almonds and scarce literature regarding them is available. Since ZEN appears to be a common toxin in tree nuts, its metabolites could also be expected, as observed in this study. Despite not being a major fungus in almonds, Alternaria toxins have been usually reported. AOH was also quantified in $12 \%$ of samples ranging from 0.34 to $0.37 \mu \mathrm{gg} / \mathrm{kg}$. In a previous work conducted by Varga et al. [22], AOH was found in one sample $(n=8)$ at $1.5 \mu \mathrm{g} / \mathrm{kg}$, more 
than three times the contamination here reported. Wang, Nie, Yan, Li, Cheng, and Chang [15] reported AOH contamination in four samples $(n=25)$ with a maximum level of $54.24 \mu \mathrm{g} / \mathrm{kg}$. On the contrary, aflatoxins are one the most studied toxins in every nut typology. AFB1 was found in one sample at $0.45 \mu \mathrm{g} / \mathrm{kg}$, complying with the regulation regarding maximum limits. Liao, et al. [23] reported contamination with AFB1 at $0.3 \mu \mathrm{g} / \mathrm{kg}$ in one almond sample $(n=9)$, similar to the concentration found in this study. Due to the toxicological potential of aflatoxins, special treatments are used in order to eliminate fungal contamination or to inactivate the toxins, such as roasting, sorting, and physical segregation [10], so it is not usual finding aflatoxins at concentrations above the maximum limits (8 for AFB1 and $10 \mu \mathrm{g} / \mathrm{kg}$ for the sum of aflatoxins).

Table 3. Occurrence of mycotoxins in the analyzed tree nuts.

\begin{tabular}{|c|c|c|c|c|}
\hline \multirow[b]{2}{*}{ Analyte } & \multirow[b]{2}{*}{ Incidence $(n,(\%))$} & \multirow[b]{2}{*}{ Mean $(\mu \mathrm{g} / \mathrm{kg})$} & \multicolumn{2}{|c|}{ Range ( $\mu \mathrm{g} / \mathrm{kg})$} \\
\hline & & & Min & Max \\
\hline \multicolumn{5}{|c|}{ Almonds $(n=17)$} \\
\hline AFB1 & $1(6)$ & 0.45 & - & - \\
\hline$\alpha-Z A L$ & $3(18)$ & 3.99 & 3.70 & 4.54 \\
\hline$\alpha-Z E L$ & $1(6)$ & 1.40 & - & - \\
\hline$\beta$-ZEL & $2(12)$ & 0.54 & 0.46 & 0.62 \\
\hline $\mathrm{AOH}$ & $2(12)$ & 0.35 & 0.34 & 0.37 \\
\hline \multicolumn{5}{|c|}{ Walnuts $(n=22)$} \\
\hline$\alpha-Z A L$ & $2(12)$ & 2.18 & 2.13 & 2.24 \\
\hline$\beta-Z A L$ & $3(18)$ & 3.13 & 1.67 & 5.24 \\
\hline$\beta-Z E L$ & $4(24)$ & 0.39 & 0.3 & 0.55 \\
\hline ZEN & $3(18)$ & 0.44 & $<\mathrm{LOQ}$ & 0.93 \\
\hline $\mathrm{AOH}$ & $9(53)$ & 0.67 & 0.29 & 1.65 \\
\hline AME & $3(18)$ & 1.63 & 1.13 & 1.95 \\
\hline ENN B1 & $1(6)$ & 1.30 & - & - \\
\hline \multicolumn{5}{|c|}{ Pistachios $(n=15)$} \\
\hline$\alpha-Z A L$ & $2(12)$ & 25.75 & 2.16 & 49.35 \\
\hline$\beta-Z A L$ & $1(6)$ & 11.86 & - & - \\
\hline$\alpha-Z E L$ & $2(12)$ & 1.50 & 1.26 & 1.74 \\
\hline$\beta-Z E L$ & $10(59)$ & 3.42 & 0.96 & 8.60 \\
\hline $\mathrm{AOH}$ & $1(6)$ & 7.75 & - & - \\
\hline
\end{tabular}

Walnuts $(n=22)$ showed contamination with seven mycotoxins, finding at least one in $59 \%$ of samples. ZEN was quantified in $18 \%$ of samples ranging from $<\mathrm{LOQ}$ to $0.93 \mu \mathrm{g} / \mathrm{kg}$. Several metabolites were also detected: $\beta$-ZEL was the most common one, present in $24 \%$ of samples varying from 0.3 to $0.55 \mu \mathrm{g} / \mathrm{kg}$; $\beta$-ZAL was found in $18 \%$ of samples and, quantitatively, meant the most relevant one at levels going from 1.67 to $5.24 \mu \mathrm{g} / \mathrm{kg}$; lastly, $\alpha$-ZAL was present in $12 \%$ of samples at 2.13 and 2.24 $\mu \mathrm{g} / \mathrm{kg}$. ENNB1, an emerging Fusarium mycotoxin, was quantified at $1.3 \mu \mathrm{g} / \mathrm{kg}$ in one sample (6\%). As previously observed in almonds, walnut samples also contained ZEN and ZEN metabolites. In the same study conducted by Wang, Nie, Yan, Li, Cheng, and Chang [15], a high contamination with ZEN was observed in one sample $(n=35)$ at $49.35 \mu \mathrm{g} / \mathrm{kg}$, whereas Arroyo-Manzanares, Huertas-Pérez, Gámiz-Gracia, and García-Campaña [12] reported the presence of ZEN in one sample $(n=6)$ at 221.8 $\mu \mathrm{g} / \mathrm{kg}$. These levels of contamination strongly vary from those here obtained, with concentrations below $1 \mu \mathrm{g} / \mathrm{kg}$. Furthermore, ZEN metabolites were quantitatively more relevant than ZEN, remarking the necessity of taken into consideration these mycotoxins when performing contaminant analysis in walnuts.

Alternaria toxins are not common mycotoxins included in tree nut studies. Nevertheless, $\mathrm{AOH}$ was extensively found at low concentrations ranging from 0.29 to $1.65 \mu \mathrm{g} / \mathrm{kg}$ in $53 \%$ of samples. AME was also present in $18 \%$ of samples at slightly higher levels, going from 1.13 up to $1.95 \mu \mathrm{g} / \mathrm{kg}$. Therefore, sensitive analytical methods are required in order to understand the incidence of these toxins. In this line, Wang, Nie, Yan, Li, Cheng, and Chang [15] quantified AOH and AME in 23\% and 31\% of the 
walnut samples analyzed $(n=35)$, respectively, with a LOQ of $2 \mu \mathrm{g} / \mathrm{kg}$. AOH was quantified in a range of $5.78-142.9 \mu \mathrm{g} / \mathrm{kg}$ and AME ranged from 1.53 to $110.5 \mu \mathrm{g} / \mathrm{kg}$. Similar to the here-presented data, Alternaria toxins resulted as the most common toxins occurring in walnuts.

Lastly, five mycotoxins were quantified in pistachios samples $(n=15)$, with at least one occurring in $80 \%$ of them. Among the matrices analyzed, pistachios resulted as the most contaminated. $\beta$-ZEL was the most prevalent mycotoxin, being detected in 59\% of samples ranging from 0.96 to $8.6 \mu \mathrm{g} / \mathrm{kg}$. $\alpha$-ZEL and $\alpha$-ZAL were both quantified in $12 \%$ of samples, ranging from 1.26 to $1.74 \mu \mathrm{g} / \mathrm{kg}$ and from 2.16 to $49.35 \mu \mathrm{g} / \mathrm{kg}$, respectively. $\beta$-ZAL was only found in one sample at $11.86 \mu \mathrm{g} / \mathrm{kg}$ and, similarly, $\mathrm{AOH}$ was found at $7.75 \mu \mathrm{g} / \mathrm{kg}$.

Quantitatively, pistachios showed a significantly heavier contamination $(p<0.05)$ when compared to almond and walnuts. In addition, the highest levels of $\mathrm{AOH}$ and $\mathrm{ZEN}$ metabolites were detected in pistachios. Although aflatoxins or ZEN have been analyzed in this matrix [22,24,25], there is scarce literature regarding the here-found toxins. Furthermore, the available validated procedures for ZEN metabolites cannot reach a high sensitivity as the here obtained ( $\mathrm{LOQ}=0.78 \mu \mathrm{g} / \mathrm{kg}$ ), with Spanjer et al. [26] establishing the LOQs at $40 \mu \mathrm{g} / \mathrm{kg}$ and Hidalgo-Ruiz, Romero-González, Martínez Vidal, and Garrido-Frenich [17] at $1 \mu \mathrm{g} / \mathrm{kg}$ for $\alpha$-ZEL. Sensitivity becomes a crucial feature in analytical procedures, even more when the contamination reported only reach a few $\mu \mathrm{g} / \mathrm{kg}$. In this line, Alcántara-Durán, Moreno-González, García-Reyes, and Molina-Díaz [16] did not find $\alpha$-ZEL occurring in pistachios despite having a low LOQ $(0.05 \mu \mathrm{g} / \mathrm{kg})$. Alternaria toxins have not been deeply studied in pistachio neither. Varga, Glauner, Berthiller, Krska, Schuhmacher, and Sulyok [22] developed a procedure for $\mathrm{AOH}$ with the LOQ at $9.6 \mu \mathrm{g} / \mathrm{kg}$, which would not have been sensitive enough for detecting the contamination here reported $(7.75 \mu \mathrm{g} / \mathrm{kg})$.

Co-occurrence of mycotoxins was observed in the three different commodities, as shown in Table 4. Walnuts presented a wide variety of combinations, including $\mathrm{AOH}$ in most of them. In total, co-occurrence happened in a $45 \%$ of walnuts samples. On the contrary, pistachios and almonds showed a lower incidence of co-occurrence, accounting for $27 \%$ and $1 \%$ of the total samples, respectively.

Table 4. Co-occurrence of mycotoxins in the analyzed tree nuts.

\begin{tabular}{|c|c|}
\hline Combinations of Mycotoxins & Incidence $(\mathrm{n},(\%))$ \\
\hline \multicolumn{2}{|c|}{ Almonds $(n=17)$} \\
\hline$\alpha-\mathrm{ZAL}+\alpha-\mathrm{ZEL}$ & $1(6)$ \\
\hline \multicolumn{2}{|l|}{ Walnuts $(n=22)$} \\
\hline $\mathrm{AOH}+\alpha-\mathrm{ZAL}$ & $1(6)$ \\
\hline $\mathrm{AOH}+\beta-\mathrm{ZEL}$ & $1(6)$ \\
\hline $\mathrm{AOH}+\mathrm{ZEN}$ & $2(12)$ \\
\hline$\alpha-\mathrm{ZAL}+\mathrm{AME}$ & $1(6)$ \\
\hline$\alpha-\mathrm{ZAL}+\beta-\mathrm{ZAL}$ & $1(6)$ \\
\hline$\alpha-Z E L+\beta-Z E L$ & $1(6)$ \\
\hline $\mathrm{AOH}+\alpha-\mathrm{ZAL}+\mathrm{ZEN}$ & $1(6)$ \\
\hline $\mathrm{AOH}+\beta-\mathrm{ZEL}+\mathrm{AME}$ & $1(6)$ \\
\hline $\mathrm{AOH}+\beta-\mathrm{ZEL}+\beta-\mathrm{ZAL}+\mathrm{AME}$ & $1(6)$ \\
\hline \multicolumn{2}{|c|}{ Pistachios $(n=15)$} \\
\hline$\alpha-Z A L+\beta-Z A L$ & $1(6)$ \\
\hline$\beta-Z A L+\beta-Z E L$ & $1(6)$ \\
\hline$\alpha-Z E L+\beta-Z E L$ & $1(6)$ \\
\hline $\mathrm{AOH}+\beta-\mathrm{ZEL}$ & $1(6)$ \\
\hline
\end{tabular}

There is a strong variability referring to the content of mycotoxins depending on several parameters including temperature, moisture, or pre- and post-harvest practices, among others. This variability observed highlights the necessity of constantly monitoring these kinds of products using highly sensitive analytical procedures in order to ensure a safe consumption. Furthermore, an investigation carried out by the EFSA [18] considered the application of potency factors for ZEN metabolites ranging 
from 0.2 to 60 times the toxicity associated with ZEN. Considering the high uncertainty related to these metabolites, the analytical procedures should include these mycotoxins that could account for future exposure assessment studies.

\subsection{Exposure Assessment}

An exposure assessment and risk characterization were performed taking into consideration the left-censored data for the more prevalent mycotoxins detected in the samples, including ZEN-derived forms, $\mathrm{AOH}$ and AME. Results are showed in Table 5.

Table 5. Risk characterization of detected mycotoxins in different population groups based on the percentage of tolerable daily intake considering four different scenarios per group: Mean and 95th percentile consumption value combined with lower and upper bound of contamination.

\begin{tabular}{|c|c|c|c|c|c|c|c|c|c|c|c|c|c|c|c|c|c|c|c|}
\hline \multirow[b]{4}{*}{ Mycotoxins } & \multirow[b]{4}{*}{$\begin{array}{c}\text { TDI or TTC } \\
(\mu \mathrm{g} / \mathrm{kg} \\
\text { bw/day) }\end{array}$} & & & \multicolumn{16}{|c|}{ Risk Characterization (\%TDI or \%TTC) } \\
\hline & & & & \multicolumn{4}{|c|}{ Child } & \multicolumn{4}{|c|}{ Teenager } & \multicolumn{4}{|c|}{ Adult } & \multicolumn{4}{|c|}{ Elderly } \\
\hline & & \multicolumn{2}{|c|}{$C(\mu \mathrm{g} / \mathrm{kg})$} & \multicolumn{2}{|c|}{ Mean } & \multicolumn{2}{|c|}{ P95th } & \multicolumn{2}{|c|}{ Mean } & \multicolumn{2}{|c|}{ P95th } & \multicolumn{2}{|c|}{ Mean } & \multicolumn{2}{|c|}{ P95th } & \multicolumn{2}{|c|}{ Mean } & \multicolumn{2}{|c|}{ P95th } \\
\hline & & LB & UB & LB & UB & LB & UB & LB & UB & LB & UB & LB & UB & LB & UB & LB & UB & LB & UB \\
\hline$\sum \mathrm{ZEN}_{\mathrm{d}}$ & 0.25 & 7.25 & 59.70 & 0.7 & 5.9 & 1.9 & 15.6 & 0.4 & 3.2 & 1.2 & 10.1 & 0.4 & 3.3 & 1.0 & 8.5 & 0.5 & 3.8 & 1.3 & 10.5 \\
\hline $\mathrm{AOH}$ & 0.0025 & 0.10 & 0.48 & 0.8 & 4.8 & 2.8 & 12.4 & 0.4 & 2.4 & 1.6 & 8.0 & 0.4 & 2.8 & 1.6 & 6.8 & 0.8 & 3.2 & 1.6 & 8.4 \\
\hline AME & 0.0025 & 0.25 & 0.82 & 2.4 & 8.0 & 6.4 & 21.2 & 1.2 & 4.4 & 4.4 & 14.0 & 1.2 & 4.4 & 3.6 & 11.6 & 1.6 & 5.2 & 4.4 & 14.4 \\
\hline
\end{tabular}

$\sum Z_{\mathrm{d} N}$ : Sum of ZEN and its derived forms $\alpha$-ZAL, $\alpha$-ZEL, $\beta$-ZAL, $\beta$-ZEL; TDI: Tolerable daily intake; TTC: Threshold of toxicological concern; C: Contamination; LB: Lower bound; UP: Upper bound; P95th: 95th percentile.

The tree nut consumption did not vary much throughout the age groups, so children with the lowest body weight showed the heaviest exposure. The percentages of relevant TDI or TTC calculated for children were two-fold higher than those for teenagers and adults, but below the maximum tolerable values established by the Scientific Committee on Food of the European Commission at $0.25 \mu \mathrm{g} / \mathrm{kg}$ bw/day for the sum of ZEN and its metabolites and $0.0025 \mu \mathrm{g} / \mathrm{kg}$ bw/day for both AOH and AME.

Under the worst-case scenario, the percentages of relevant TDI or TTC calculated for children meant between a tenth and a fifth of the established safety levels. Nevertheless, it might be a concern since $\mathrm{ZEN}$, its derived forms, $\mathrm{AOH}$ and $\mathrm{AME}$, can be found in different commodities such as cereals and other vegetal products, which are more commonly consumed by children.

The results evidence a negligible exposure of these mycotoxins due to ready-to-eat nut products, but these scarcely studied mycotoxins might be of importance when performing risk assessment through total diet studies.

\section{Conclusions}

An analytical method based on QuEChERS extraction and ultra-high performance liquid chromatography coupled with high-resolution mass spectrometry was validated for the simultaneous detection of eighteen mycotoxins in ready-to-eat almonds, walnuts, and pistachios. The features fulfilled the requirements set by the European Union regarding selectivity, linearity, trueness, precision, with high sensitivity based on limits of quantification. The procedure was then applied to almonds $(n=17)$, walnuts $(n=22)$, and pistachios $(n=15)$ acquired from Italian markets. The most relevant mycotoxin in almonds was $\alpha$-zearalanol, found in $18 \%$ of samples $(n=17)$ ranging from 3.70 to 4.54 $\mu \mathrm{g} / \mathrm{kg}$. Walnut samples showed frequent contamination with alternariol, present in $53 \%$ of samples $(n=22)$ at levels from 0.29 up to $1.65 \mu \mathrm{g} / \mathrm{kg}$. Pistachios were the most contaminated commodity, with $\beta$-zearalenol as the most prevalent toxin present in $59 \%$ of samples ranging from 0.96 to 8.60 $\mu \mathrm{g} / \mathrm{kg}$. In the worst-case scenario, the exposure to zearalenone-derived forms accounted for $15.6 \%$ of the tolerable daily intake, whereas it meant $12.4 \%$ and $21.2 \%$ of the threshold of toxicological concern for alternariol and alternariol monomethyl-ether, respectively. The results highlighted the extensive presence of zearalenone-derived forms and Alternaria toxins in ready-to-eat nut products. The relevance showed in this study suggests the inclusion of these mycotoxins in analytical methods to 
perform more realistic risk assessments, even more when only little toxicological data are available for setting a proper legislation.

\section{Materials and Methods}

\subsection{Chemicals and Reagents}

Methanol (MeOH), acetonitrile water, and formic acid (FA) for LC mobile phase (HPLC grade) were purchased from Merck (Darmstadt, Germany). Sodium chloride ( $\mathrm{NaCl}$ ), ammonium formate $\left(\mathrm{NH}_{4} \mathrm{HCO}_{2}\right)$, magnesium sulfate $\left(\mathrm{MgSO}_{4}\right)$, and octadecyl carbon chain-bonded silica (C18) were acquired from Sigma Aldrich (Milan, Italy). Eighteen mycotoxin standards (purity $>98 \%$ ) including aflatoxins (AFB1, AFB2, AFG1, and AFG2), zearalenone (ZEN), $\alpha$-zearalanol ( $\alpha$-ZAL), $\alpha$-zearalenol ( $\alpha$-ZEL), $\beta$-zearalanol ( $\beta$-ZAL), neosolaniol (NEO), T-2 toxin, HT-2 toxin, enniatins (A, A1, B, and $\mathrm{B} 1)$, alternariol monomethyl ether (AME), and alternariol $(\mathrm{AOH})$ were obtained from Sigma-Aldrich (Milan, Italy).

Stock solutions of each mycotoxin were built by dissolving $1 \mathrm{mg}$ of solid reference standard in $1 \mathrm{~mL}$ of methanol. An intermediate mixed solution containing all the mycotoxins at a concentration of $30 \mu \mathrm{g} / \mathrm{mL}$ was obtained after mixing individual stock solutions and diluting in $\mathrm{MeOH}: \mathrm{H}_{2} \mathrm{O}(70: 30 \mathrm{v} / \mathrm{v})$ $0.1 \%$ formic acid. Working standard solutions at $1.6,0.4,0.08 \mu \mathrm{g} / \mathrm{mL}$ were used for spiking experiments (fortification levels at 20,5, and $1 \mu \mathrm{g} / \mathrm{kg}$ ). All solutions were stored in safe conditions at $-20^{\circ} \mathrm{C}$ in screw-capped glass vials.

\subsection{Sampling}

Fifty-four commercially available nut products were randomly purchased from supermarkets located in the Campania Region, Southern Italy. Products were classified as walnuts $(n=22)$, pistachios $(n=15)$, and almonds $(n=17)$ and sent to the laboratory in their original packages. Samples were kept in dark and cool conditions as recommended by the manufacturer, and analyses were carried out within five days after receiving them.

\subsection{Sample Preparation}

A procedure previously developed by Cunha, Sá, and Fernandes [14] was used as the starting point, with some modifications. Briefly, $10 \mathrm{~g}$ of homogenized sample was introduced into a $50 \mathrm{~mL}$ Falcon tube (Conical Polypropylene Centrifuge Tube; Thermo Fisher Scientific, Milan, Italy) and $5 \mathrm{~mL}$ of distilled water and $5 \mathrm{~mL}$ of acetonitrile containing $1 \%$ formic acid $(v / v)$ were added. The sample was vortexed (ZX3; VEPL Scientific, Usmate, Italy) for $2 \mathrm{~min}$. Then, $0.5 \mathrm{~g}$ of sodium chloride and $2.0 \mathrm{~g}$ of anhydrous sulfate sodium were added. The tube was manually shaken for $1 \mathrm{~min}$ and then centrifuged (X3R Heraeus Multifuge; Thermo Fisher Scientific, Kalkberg, Germany) for $10 \mathrm{~min}$ at $4907 \times \mathrm{g}$ at room temperature. The supernatant $(1.5 \mathrm{~mL})$ was transferred to a $15 \mathrm{~mL}$ Falcon tube containing $50 \mathrm{mg}$ of C18 sorbent, then vortexed for $1 \mathrm{~min}$ and centrifuged for $3 \mathrm{~min}$ at $4907 \times \mathrm{g}$ at room temperature. Lastly, $0.4 \mathrm{~mL}$ were collected, filtered through a $0.22 \mu \mathrm{m}$ filter and injected into the UHPLC-Q-Orbitrap HRMS instrument.

\subsection{UHPLC-Q-Orbitrap HRMS Analysis}

Detection and quantification analysis were performed using a Dionex UltiMate ${ }^{\circledR} 3000$ system consisting of a quaternary UHPLC pump working at 1250 bar (125 MPa), a degassing system, an autosampler device, and a thermostatically controlled column coupled with a Q-Exactive mass spectrometer (ThermoFisher Scientific, Waltham, MA, USA). Chromatographic separation of analytes was carried out with a thermostated Luna Omega Polar C18 column $(50 \times 2.1 \mathrm{~mm}, 1.6 \mu \mathrm{m}$; Phenomenex, Torrance, CA, USA) kept at $30^{\circ} \mathrm{C}$. Water (A) and methanol (B), both containing $0.1 \%$ formic acid and $5 \mathrm{mM}$ ammonium acetate were used as mobiles phases. The gradient profile started with $0 \% \mathrm{~B}$ for $1 \mathrm{~min}$, increased to $95 \%$ B over $1 \mathrm{~min}$ and kept for $0.5 \mathrm{~min}$. Next, the gradient linearly decreased to $75 \%$ 
B over $2.5 \mathrm{~min}$ and decreased again until $60 \%$ in $1 \mathrm{~min}$. Lastly, the gradient went back to $0 \%$ in $0.5 \mathrm{~min}$ and held for $1.5 \mathrm{~min}$ for column re-equilibration. Total run time was $8 \mathrm{~min}$ with an injection volume of $5 \mu \mathrm{L}$ and a flow rate of $0.4 \mathrm{~mL} / \mathrm{min}$.

The mass spectrometer operated in positive and negative ion modes by setting 2 scan events: Full ion MS and all ion fragmentation (AIF). The following settings were used in full MS mode: Resolution power of 35,000 FWHM (defined for $m / z$ 200), automatic gain control (AGC) target $1 \times 10^{6}$, scan range 100-1000 m/z, injection time set to $200 \mathrm{~ms}$, and scan rate set at $2 \mathrm{scans} / \mathrm{s}$. The ion source parameters were: Capillary temperature $290^{\circ} \mathrm{C}$, S-lens RF level 50, spray voltage $4 \mathrm{kV}$ (-kV en ESImode), sheath gas pressure $\left(\mathrm{N}_{2}>95 \%\right) 35$, auxiliary gas $\left(\mathrm{N}_{2}>95 \%\right) 10$, and auxiliary gas heater temperature $305^{\circ} \mathrm{C}$. The AIF mode used the following settings in both modes: Scan time $=0.10 \mathrm{~s}$, maximum injection time $=200 \mathrm{~ms}$; mass resolving power $=17,500 \mathrm{FWHM}$, ACG target $=1 \times 10^{5}$, scan range $=100-1000 \mathrm{~m} / \mathrm{z}$, retention time window 30s, and isolation window $5.0 \mathrm{~m} / \mathrm{z}$. The collision energy and Orbitrap-MS parameters corresponding for each analyte were individually optimized in a previous work of our group [27]. The mass spectrometer was regularly calibrated using calibration solutions provided by ThermoFisher during three-day intervals and before each sequence. Retention time, elemental composition, theoretical and measured mass, accurate mass error, collision energy, and product ions for the analyzed compounds are shown in Table 6. A mass tolerance of 5 ppm was set for identification and confirmation of the molecular ion and both products. For accurate mass measurement, identification, and confirmation were performed at a mass tolerance of 5 ppm for the molecular ion and for both fragments. Xcalibur software, v.3.1.66.10. was used in order to analyze and process the data.

Table 6. UHPLC-HRMS parameters corresponding to the here-analyzed mycotoxins.

\begin{tabular}{|c|c|c|c|c|c|c|c|c|}
\hline Analyte & $\begin{array}{c}\text { Retention Time } \\
\text { (min) }\end{array}$ & $\begin{array}{c}\text { Elemental } \\
\text { Composition }\end{array}$ & Adduct Ion & $\begin{array}{l}\text { Theoretical } \\
\text { Mass }(\mathrm{m} / \mathrm{z})\end{array}$ & $\begin{array}{c}\text { Measured Mass } \\
(\mathrm{m} / \mathrm{z})\end{array}$ & $\begin{array}{c}\text { Accuracy } \\
(\Delta \text { ppm) }\end{array}$ & $\begin{array}{l}\text { Collision } \\
\text { Energy (eV) }\end{array}$ & $\begin{array}{l}\text { Product Ions } \\
(\mathrm{m} / \mathrm{z})\end{array}$ \\
\hline NEO & 4.25 & $\mathrm{C}_{19} \mathrm{H}_{26} \mathrm{O}_{8}$ & $\left(\mathrm{M}+\mathrm{NH}_{4}\right)^{+}$ & 400.19659 & 400.19632 & -0.67 & 10 & $\begin{array}{l}305.13803 \\
141.00530\end{array}$ \\
\hline AFG2 & 4.52 & $\mathrm{C}_{17} \mathrm{H}_{14} \mathrm{O}_{7}$ & $(\mathrm{M}+\mathrm{H})^{+}$ & 331.08123 & 331.08078 & -1.36 & 37 & $\begin{array}{l}313.07010 \\
245.08032\end{array}$ \\
\hline AFG1 & 4.55 & $\mathrm{C}_{17} \mathrm{H}_{12} \mathrm{O}_{7}$ & $(\mathrm{M}+\mathrm{H})^{+}$ & 329.06558 & 329.06549 & -0.27 & 40 & $\begin{array}{l}243.06467 \\
200.04640\end{array}$ \\
\hline AFB2 & 4.60 & $\mathrm{C}_{17} \mathrm{H}_{14} \mathrm{O}_{6}$ & $(\mathrm{M}+\mathrm{H})^{+}$ & 315.08631 & 315.08615 & -0.51 & 36 & $\begin{array}{l}287.09064 \\
259.05945\end{array}$ \\
\hline AFB1 & 4.64 & $\mathrm{C}_{17} \mathrm{H}_{12} \mathrm{O}_{6}$ & $(\mathrm{M}+\mathrm{H})^{+}$ & 313.07066 & 313.07053 & -0.42 & 36 & $\begin{array}{l}285.07489 \\
269.04373\end{array}$ \\
\hline HT-2 & 4.74 & $\mathrm{C}_{22} \mathrm{H}_{32} \mathrm{O}_{8}$ & $\left(\mathrm{M}+\mathrm{NH}_{4}\right)^{+}$ & 442.24354 & 442.24323 & -0.70 & 27 & $\begin{array}{l}263.12744 \\
215.10641\end{array}$ \\
\hline$\alpha-\mathrm{ZAL}$ & 4.81 & $\mathrm{C}_{18} \mathrm{H}_{26} \mathrm{O}_{5}$ & $(\mathrm{M}-\mathrm{H})^{-}$ & 321.17044 & 321.17065 & 0.65 & 29 & $\begin{array}{c}259.09497 \\
91.00272\end{array}$ \\
\hline$\alpha-Z E L$ & 4.83 & $\mathrm{C}_{18} \mathrm{H}_{24} \mathrm{O}_{5}$ & $(\mathrm{M}-\mathrm{H})^{-}$ & 319.15510 & 319.15500 & -0.31 & 36 & $\begin{array}{l}174.95604 \\
129.01947\end{array}$ \\
\hline $\mathrm{T}-2$ & 4.84 & $\mathrm{C}_{24} \mathrm{H}_{34} \mathrm{O}_{9}$ & $\left(\mathrm{M}+\mathrm{NH}_{4}\right)^{+}$ & 484.25411 & 484.25430 & 0.39 & 23 & $\begin{array}{l}215.10603 \\
185.09561\end{array}$ \\
\hline $\mathrm{AOH}$ & 4.85 & $\mathrm{C}_{14} \mathrm{H}_{10} \mathrm{O}_{5}$ & $(\mathrm{M}-\mathrm{H})^{-}$ & 257.04555 & 257.04581 & 1.01 & -32 & $\begin{array}{l}215.03490 \\
213.05569\end{array}$ \\
\hline$\beta-\mathrm{ZAL}$ & 4.94 & $\mathrm{C}_{18} \mathrm{H}_{26} \mathrm{O}_{5}$ & $(\mathrm{M}-\mathrm{H})^{-}$ & 321.17044 & 321.17059 & 0.47 & 40 & $\begin{array}{c}259.09497 \\
91.00272\end{array}$ \\
\hline$\beta$-ZEL & 4.97 & $\mathrm{C}_{18} \mathrm{H}_{24} \mathrm{O}_{5}$ & $(\mathrm{M}-\mathrm{H})^{-}$ & 319.15510 & 319.15500 & -0.31 & 36 & $\begin{array}{l}174.95604 \\
160.97665\end{array}$ \\
\hline ZEN & 5.01 & $\mathrm{C}_{18} \mathrm{H}_{22} \mathrm{O}_{5}$ & $(\mathrm{M}+\mathrm{H})^{+}$ & 317.13945 & 317.13928 & -0.54 & -32 & $\begin{array}{l}175.03989 \\
131.05008\end{array}$ \\
\hline AME & 5.13 & $\mathrm{C}_{15} \mathrm{H}_{12} \mathrm{O}_{5}$ & $(\mathrm{M}-\mathrm{H})^{-}$ & 271.06120 & 271.06140 & 0.74 & -36 & $\begin{array}{l}256.03751 \\
228.04276\end{array}$ \\
\hline ENN B & 5.56 & $\mathrm{C}_{33} \mathrm{H}_{57} \mathrm{~N}_{3} \mathrm{O}_{9}$ & $\left(\mathrm{M}+\mathrm{NH}_{4}\right)^{+}$ & 657.44331 & 657.44348 & 0.26 & 50 & $\begin{array}{l}214.14320 \\
196.13280\end{array}$ \\
\hline ENN B1 & 5.68 & $\mathrm{C}_{34} \mathrm{H}_{59} \mathrm{~N}_{3} \mathrm{O}_{9}$ & $\left(\mathrm{M}+\mathrm{NH}_{4}\right)^{+}$ & 671.45986 & 671.45935 & -0.76 & 48 & $\begin{array}{l}214.14343 \\
196.13295\end{array}$ \\
\hline ENN A1 & 5.82 & $\mathrm{C}_{35} \mathrm{H}_{61} \mathrm{~N}_{3} \mathrm{O}_{9}$ & $\left(\mathrm{M}+\mathrm{NH}_{4}\right)^{+}$ & 685.47461 & 685.47449 & -0.18 & 48 & $\begin{array}{l}228.15900 \\
210.14847\end{array}$ \\
\hline ENN A & 5.99 & $\mathrm{C}_{36} \mathrm{H}_{63} \mathrm{~N}_{3} \mathrm{O}_{9}$ & $\left(\mathrm{M}+\mathrm{NH}_{4}\right)^{+}$ & 699.49026 & 699.48987 & -0.56 & 43 & $\begin{array}{l}228.15900 \\
210.14847\end{array}$ \\
\hline
\end{tabular}

\subsection{Validation Parameters}

An in-house validation study was carried out for the three different matrices here analyzed following the EU Commission Decision 2002/657/EC guidelines referring to linearity, selectivity, trueness, 
intra-day precision (repeatability), inter-day precision (reproducibility), and sensitivity expressed as LOQs [28]. Linearity was determined by injecting a series of neat solvent and matrix-matched calibration curves at eight concentrations levels ranging from 0.2 to $200 \mathrm{ng} / \mathrm{mL}$ with a deviation of $\leq 20 \%$ for each calibration level. The coefficient of determination was calculated using the means of the least square approach. For evaluating a potential interference of the matrix, the slopes corresponding to each linear function were compared. The $\%$ SSE occurred when a deviation $\geq 20 \%$ was observed after comparing both slopes. The selectivity of the method was assessed by injecting ten blank samples, observing no peaks that could interfere in the same retention time area as the analytes, considering a mass error of $5 \mathrm{ppm}$. Trueness was evaluated through recovery studies, spiking three blank samples at three different fortification levels: 1,5 , and $20 \mu \mathrm{g} / \mathrm{kg}$. The measurements were made during three non-consecutive days. Values ranging from 70 to $120 \%$ of recovery were considered as optimal. Precision was assessed in terms of repeatability (relative standard deviation after three determinations in a single day, $\mathrm{RSD}_{\mathrm{r}}$ ) and reproducibility (relative standard deviation after determinations in triplicate on three non-consecutive days, $\mathrm{RSD}_{\mathrm{R}}$ ). Sensitivity was determined through the LOQ for each analyte, which was established as the minimum concentration with a linear response that can be observed with a deviation $\leq 20 \%$ considering a mass error of $5 \mathrm{ppm}$.

\subsection{Exposure Assessment}

A deterministic approach was followed for performing the exposure assessment. The latest data consumption published by the Italian National Food Consumption Survey INRAN-SCAI 2005-06 were considered [29]. The commodities here analyzed were all included in the "nuts" category according to the survey, so exposure assessment was performed considering both the mean and the 95th percentile values. Population was divided in four age groups: Children (3-9.9 years) average consumption $6.4 \mathrm{~g} /$ day, P95 $17.0 \mathrm{~g} /$ day; teenagers (10-17.9 years) average consumption 7 g/day, P95 22.3 g/day; adults (18-65 years) average consumption $9.5 \mathrm{~g} /$ day, P95 $24.7 \mathrm{~g} /$ day; and elderly (65 < years) average consumption $11.1 \mathrm{~g} /$ day, P95 $30.7 \mathrm{~g} /$ day. The mean body weights attached to each group were 26.1, $52.6,69.7$, and $70.1 \mathrm{~kg}$, respectively, as detailed in the INRAN-SCAI 2005-06 survey. The probable daily intake (PDI) values were calculated using the next equation:

$$
\mathrm{PDI}=\mathrm{C} \times \mathrm{I} / \mathrm{bw},
$$

where $C$ represents the contamination (for the lower or upper bound) of each mycotoxin $(\mu \mathrm{g} / \mathrm{kg}) ;$ accounts for the mean or 95th percentile consumption established for each age group (g/day); and bw means the body weight assigned to its corresponding age group $(\mathrm{kg})$. Once the PDIs were calculated, the tolerable daily intakes (TDIs) established for the detected mycotoxins were considered for performing the risk characterization. In case of finding a mycotoxin without any TDI assigned by the EFSA yet, a threshold of toxicological concern (TTC) was used. The risk characterization was calculated following the next equation:

$$
\% \mathrm{TDI}=\mathrm{PDI} / \mathrm{TDI} \times 100,
$$

Because of the high proportion of left-censored data, two scenarios of exposure were defined considering negative samples as zero or LOQ for the lower-bound and upper-bound, respectively.

\subsection{Statistical Analysis}

Validation experiments were conducted in triplicate and expressed as mean values alongside the corresponding relative standard deviation (RSD, \%). The normality was evaluated through Saphiro-Wilk test and multivariant analysis was carried out using the Kruskal-Wallis test in order to compare the contamination levels among different matrices. A $p$-value $<0.05$ was considered as significant. The statistical software package IBM SPSS version 25 was used for data analysis. 
Author Contributions: Conceptualization, A.R. and Y.R.-C.; methodology, G.G. and Y.R.-C.; validation, L.C. and A.N.; formal analysis, L.I. and A.N.; investigation, L.C. and L.I.; data curation, A.N.; writing-original draft preparation, A.N.; writing-review and editing, Y.R.-C.; supervision, A.R. and Y.R.-C. All authors have read and agreed to the published version of the manuscript.

Funding: This research received no external funding.

Conflicts of Interest: The authors declare no conflict of interest.

\section{References}

1. De Souza, R.G.M.; Schincaglia, R.M.; Pimentel, G.D.; Mota, J.F. Nuts and human health outcomes: A systematic review. Nutrients 2017, 9, 1311. [CrossRef] [PubMed]

2. Becerra-Tomás, N.; Paz-Graniel, I.; Kendall, C.W.C.; Kahleova, H.; Rahelić, D.; Sievenpiper, J.L.; Salas-Salvadó, J. Nut consumption and incidence of cardiovascular diseases and cardiovascular disease mortality: A meta-analysis of prospective cohort studies. Nutr. Rev. 2019, 77, 691-709. [CrossRef] [PubMed]

3. Carughi, A.; Feeney, M.J.; Kris-Etherton, P.; Fulgoni, V.; Kendall, C.W.C.; Bulló, M.; Webb, D. Pairing nuts and dried fruit for cardiometabolic health. Nutr. J. 2016, 15, 23. [CrossRef] [PubMed]

4. Del Gobbo, L.C.; Falk, M.C.; Feldman, R.; Lewis, K.; Mozaffarian, D. Effects of tree nuts on blood lipids, apolipoproteins, and blood pressure: Systematic review, meta-analysis, and dose-response of 61 controlled intervention trials. Am. J. Clin. Nutr. 2015, 102, 1347-1356. [CrossRef] [PubMed]

5. International Nut and Dried Fruit Council. Nuts and Dried Fruits Global Statistical Review 2018/2019. Available online: https://www.nutfruit.org/industry/technical-resources?category=statistical-yearbooks (accessed on 18 May 2020).

6. Sataque Ono, E.Y.; Hirozawa, M.T.; Omori, A.M.; de Oliveira, A.J.; Ono, M.A. Chapter 19-Mycotoxins in Nuts and Seeds. In Nuts and Seeds in Health and Disease Prevention, 2nd ed.; Preedy, V.R., Watson, R.R., Eds.; Academic Press: San Diego, CA, USA, 2020; pp. 255-270. [CrossRef]

7. Marin, S.; Ramos, A.J.; Cano-Sancho, G.; Sanchis, V. Mycotoxins: Occurrence, toxicology, and exposure assessment. Food Chem. Toxicol. 2013, 60, 218-237. [CrossRef] [PubMed]

8. European Commission. Commission Regulation (EC) No 1881/2006 of 19 December 2006 setting maximum levels for certain contaminants in foodstuffs. Off. J. Eur. Union 2006, 364, 5-24.

9. European Commission. Commission Regulation (EU) No 165/2010 of 26 February 2010 amending Regulation (EC) No 1881/2006 setting maximum levels for certain contaminants in foodstuffs as regards aflatoxins (Text with EEA relevance). Off. J. Eur. Union 2011, 50, 8-12.

10. Marín, S.; Ramos, A.J. Chapter 17-Molds and mycotoxins in nuts. In Food Hygiene and Toxicology in Ready-to-Eat Foods; Kotzekidou, P., Ed.; Academic Press: San Diego, CA, USA, 2016; pp. 295-312.

11. Escrivá, L.; Oueslati, S.; Font, G.; Manyes, L. Alternaria mycotoxins in food and feed: An overview. J. Food Qual. 2017, 2017, 1569748. [CrossRef]

12. Arroyo-Manzanares, N.; Huertas-Pérez, J.F.; Gámiz-Gracia, L.; García-Campaña, A.M. A new approach in sample treatment combined with UHPLC-MS/MS for the determination of multiclass mycotoxins in edible nuts and seeds. Talanta 2013, 115, 61-67. [CrossRef]

13. Azaiez, I.; Giusti, F.; Sagratini, G.; Mañes, J.; Fernández-Franzón, M. Multi-mycotoxins analysis in dried fruit by LC/MS/MS and a modified QuEChERS procedure. Food Anal. Methods 2014, 7, 935-945. [CrossRef]

14. Cunha, S.C.; Sá, S.V.M.; Fernandes, J.O. Multiple mycotoxin analysis in nut products: Occurrence and risk characterization. Food Chem. Toxicol. 2018, 114, 260-269. [CrossRef] [PubMed]

15. Wang, Y.; Nie, J.; Yan, Z.; Li, Z.; Cheng, Y.; Chang, W. Occurrence and co-occurrence of mycotoxins in nuts and dried fruits from China. Food Control 2018, 88, 181-189. [CrossRef]

16. Alcántara-Durán, J.; Moreno-González, D.; García-Reyes, J.F.; Molina-Díaz, A. Use of a modified QuEChERS method for the determination of mycotoxin residues in edible nuts by nano flow liquid chromatography high resolution mass spectrometry. Food Chem. 2019, 279, 144-149. [CrossRef] [PubMed]

17. Hidalgo-Ruiz, J.L.; Romero-González, R.; Martínez Vidal, J.L.; Garrido Frenich, A. Determination of mycotoxins in nuts by ultra high-performance liquid chromatography-tandem mass spectrometry: Looking for a representative matrix. J. Food Compos. Anal. 2019, 82, 103228. [CrossRef]

18. EFSA Panel on Contaminants in the Food Chain. Appropriateness to set a group health-based guidance value for zearalenone and its modified forms. EFSA J 2016, 14, e04425. [CrossRef] 
19. European Food Safety Authority; Arcella, D.; Eskola, M.; Gómez Ruiz, J.A. Dietary exposure assessment to Alternaria toxins in the European population. EFSA J. 2016, 14, e04654. [CrossRef]

20. Sentandreu, E.; Peris-Díaz, M.D.; Sweeney, S.R.; Chiou, J.; Muñoz, N.; Tiziani, S. A survey of orbitrap all ion fragmentation analysis assessed by an R Metabolist package to study small-molecule metabolites. Chromatographia 2018, 81, 981-994. [CrossRef]

21. Škrbić, B.; Živančev, J.; Godula, M. Multimycotoxin analysis of crude extracts of nuts with ultra-high performance liquid chromatography/tandem mass spectrometry. J. Food Compos. Anal. 2014, 34, 171-177. [CrossRef]

22. Varga, E.; Glauner, T.; Berthiller, F.; Krska, R.; Schuhmacher, R.; Sulyok, M. Development and validation of a (semi-)quantitative UHPLC-MS/MS method for the determination of 191 mycotoxins and other fungal metabolites in almonds, hazelnuts, peanuts and pistachios. Anal. Bioanal. Chem. 2013, 405, 5087-5104. [CrossRef]

23. Liao, C.-D.; Wong, J.W.; Zhang, K.; Yang, P.; Wittenberg, J.B.; Trucksess, M.W.; Hayward, D.G.; Lee, N.S.; Chang, J.S. Multi-mycotoxin analysis of finished grain and nut products using ultrahigh-performance liquid chromatography and positive electrospray ionization-quadrupole orbital ion trap high-resolution mass spectrometry. J. Agric. Food Chem. 2015, 63, 8314-8332. [CrossRef]

24. García-Cela, E.; Ramos, A.J.; Sanchis, V.; Marin, S. Risk management towards food safety objective achievement regarding to mycotoxins in pistachio: The sampling and measurement uncertainty issue. Food Control 2013, 31, 392-402. [CrossRef]

25. Luttfullah, G.; Hussain, A. Studies on contamination level of aflatoxins in some dried fruits and nuts of Pakistan. Food Control 2011, 22, 426-429. [CrossRef]

26. Spanjer, M.C.; Rensen, P.M.; Scholten, J.M. LC-MS/MS multi-method for mycotoxins after single extraction, with validation data for peanut, pistachio, wheat, maize, cornflakes, raisins and figs. Food Addit. Contam. Part A 2008, 25, 472-489. [CrossRef] [PubMed]

27. Castaldo, L.; Graziani, G.; Gaspari, A.; Izzo, L.; Tolosa, J.; Rodríguez-Carrasco, Y.; Ritieni, A. Target analysis and retrospective screening of multiple mycotoxins in pet food using UHPLC-Q-Orbitrap hrms. Toxins 2019, 11, 434. [CrossRef]

28. European Commission. Commission Decision 2002/657/EC of 12 August 2002 implementing Council Directive 96/23/EC concerning the performance of analytical methods and the interpretation of results. Off. J. Eur. Union 2002, 221, 8-36.

29. Leclercq, C.; Arcella, D.; Piccinelli, R.; Sette, S.; Le Donne, C. The italian national food consumption survey INRAN-SCAI 2005-06: Main results in terms of food consumption. Public Health Nutr. 2009, 12, 2504-2532. [CrossRef]

(C) 2020 by the authors. Licensee MDPI, Basel, Switzerland. This article is an open access article distributed under the terms and conditions of the Creative Commons Attribution (CC BY) license (http://creativecommons.org/licenses/by/4.0/). 